\title{
The role of academic mentors for Latino/a adolescents exposed to community violence
}

\author{
Kayla J. Fike $^{1} \odot$ | Rosario Ceballo $^{1}$ | Traci M. Kennedy ${ }^{2}$
}

\author{
${ }^{1}$ Departments of Psychology and Women's \\ Studies, University of Michigan, Ann Arbor, \\ Michigan \\ ${ }^{2}$ Department of Psychiatry, School of \\ Medicine, University of Pittsburgh, \\ Pittsburgh, Pennsylvania

\section{Correspondence} \\ Kayla Fike, University of Michigan, \\ 530 Church St., Ann Arbor, MI 48109. \\ Email: kjfike@umich.edu
}

\begin{abstract}
Aims: We examined the protective role of academic mentors for Latino/a youth exposed to community violence. We tested whether the mentor facilitation of positive growth and mentor school involvement moderated the relations between exposure to violence and Latino/a youth's educational values, school effort, and academic efficacy.

Methods: We used hierarchical linear regressions to examine these relations among 210 Latino/a high school students.
\end{abstract}

Results: Witnessing violence and personal victimization was negatively related to all three educational outcomes. Mentor school involvement was positively related to all three educational outcomes, whereas mentor facilitation of growth was positively related to educational values only. A significant interaction between witnessing violence and mentor school involvement indicated that the negative relation between witnessing violence and educational values weakened at high levels of mentor school involvement.

Conclusion: We discuss the benefits of academic mentoring and exploring effective mentoring characteristics with Latino/a youth exposed to violence.

\section{KEYWORDS}

adolescent, Latino/a Americans, mentors, regression analyses, schools, students, Violence

Latino/a adolescents living in urban, low-income neighborhoods are disproportionately exposed to community violence (Buka, Stichick, Birdthistle, \& Earls, 2001; Crouch, Hanson, Saunders, Kilpatrick, \& Resnick, 2000). Community violence exposure (CVE) has been defined as the instances of interpersonal harm or threats of harm 
that youth either witness or personally experience within their neighborhood (Kennedy \& Ceballo, 2014). The high rates of CVE for Latino/a youth are especially alarming given the negative associations between CVE and youth's psychological well-being, including symptoms of anxiety, depression, externalizing problem behaviors, and posttraumatic stress disorder (PTSD; Fowler, Tompsett, Braciszewski, Jacques-Tiura, \& Baltes, 2009; Kennedy \& Ceballo, 2013). However, the majority of CVE research has sampled African-American youth (Poquiz \& Fite, 2018). In this paper, "Latino/a" refers to people with ethnic roots stemming from Mexico, Central and South America, and the Caribbean who reside in the United States. For example, people with Dominican ethnic backgrounds (from the Dominican Republic) make up a large number of immigrants to the Northeastern United States; thus, it is critical to better understand the implications of CVE for Latino/a adolescents, an equally at risk yet understudied group.

The psychological impact of CVE is well-documented (Jocson, Alers-Rojas, Ceballo, \& Arkin, 2018), but fewer studies examine the relation between CVE and educational outcomes. Among these studies, many focus on "objective" indicators of academic functioning, such as grade point average (GPA), school attendance, or standardized test scores (York, Gibson, \& Rankin, 2015). The results of these studies show negative associations between CVE and academic functioning among Latino/a youth (Henrich, Schwab-Stone, Fanti, Jones, \& Ruchkin, 2004; Schwartz \& Gorman, 2003). However, researchers have suggested broadening the measurement of academic functioning to include more nuanced markers of academic success (García Coll et al., 1996; York, Gibson, \& Rankin, 2015). York et al. (2015) sought to clarify the concept of academic success, noting that GPA is a metric that assesses a student's ability to meet school or classroom standards rather than academic success per se. They suggest that the traditional indicators of academic functioning, such as GPA and grades, may not be valid measures of student learning or cognitive growth, may vary across institutions, and may be prioritized primarily due to their accessibility. Moreover, objective indicators of academic success might be the endpoints of intermediary processes more amenable to intervention. As such, research with the youth of color should attend to potential precursors to traditional measures of academic success. For instance, Borofsky, Kellerman, Baucom, Oliver, \& Margolin (2013) investigated the longitudinal relations between CVE and academic achievement (i.e., GPA) and school engagement (e.g., valuing education, school belonging, and interest in school activities). They found that CVE was negatively associated with both school engagement and GPA. Further, reduced school engagement partially mediated the negative relation between CVE and GPA. These findings suggest that CVE may disrupt academic success by affecting students' ability to engage or focus in school. Therefore, school engagement might be an earlier indicator of the negative impact of CVE on academic success and could be an effective target for intervention.

\section{Academic mentoring and educational outcomes}

While the research regarding academic risk among violence-exposed Latino/a youth deserves careful attention, emphasis must be placed not only on understanding the processes of risk, but also on promotive and protective factors that can help bolster academic success and minimize these risk processes. Academic mentors are one source of support who positively contribute to Latino/a youth's academic success (Ceballo, Huerta, \& Epstein-Ngo, 2010; Sánchez, Esparza, \& Colón, 2008). Academic mentoring can occur through formal mentoring programs with professionally trained staff or volunteers, or naturally through youth's connections to adults in their social networks. Natural mentors are defined as nonparental adults, both within and outside of an adolescent's family, who are not motivated to mentor an adolescent through a formal mentoring program such as Big Brothers/Big Sisters of America (Zimmerman, Bingenheimer, \& Notaro, 2002). Nationally representative data indicate that adolescents with natural mentors are more likely to finish high school and attend college than adolescents without mentors (DuBois \& Silverthorn, 2005). Research with racial/ethnic minority youth has also found that having a natural mentor is associated with positive academic outcomes (Hurd, Sánchez, Zimmerman, \& Caldwell, 2012; Zimmerman et al., 2002). Studies with Latino/a youth, in particular, have found positive associations between academic mentoring and academic outcomes, such as greater expectancies for success, higher educational expectations, fewer school absences, and a greater sense of school belonging (Sánchez et al., 2008). Moreover, 
academic mentoring is associated with higher grades for youth in the context of CVE and other community-level risks (Herrera, DuBois, \& Grossman, 2013).

Yet, the qualities of an effective mentoring relationship are still debated (See DuBois, Portillo, Rhodes, Silverthorn, \& Valentine, 2011, and Herrera et al., 2013 for reviews). Some important aspects of effective mentoring relationships include encouragement toward future goals (Secada et al., 1998) and guidance in preparation for college (Arellano \& Padilla, 1996; Ceballo, 2004). These findings suggest that effective mentoring relationships may require more than the mere presence of an academic mentor (Lyons \& McQuillin, 2018). Indeed, Spencer and Rhodes (2014) posit that mentoring relationships should encourage personal and academic growth for youth, including maintaining psychological health, cultivating meaningful relationships with others, and pursuing skill development in society. In Morales' (2010) qualitative study with Latino/a and African American urbanresiding youth, one of the most important aspects of mentoring relationships identified by youth was mentor encouragement toward greater academic engagement. Youth reported that their mentors encouraged them to cultivate high educational aspirations and strong future orientations. Other research with Latino/a youth from lowincome families highlights the ways natural mentors challenge mentees to set goals and teach them how to accomplish those goals (Stanton-Salazar \& Spina, 2003).

Another aspect of mentor relationships that enhances Latino/a youth's positive academic outcomes is mentors' involvement in their mentees' education (Zimmerman et al., 2002). This involvement can manifest in a variety of ways, from sharing experiences to organizing activities focused on academic engagement (Nakkula \& Harris, 2013). However, there is a gap in the literature on effective mentoring that explicitly examines how academic mentors should be involved in their mentees' schools. In one study of 140 Latino/a students from an urban high school, more frequent mentor-mentee contact and a wide range of educational supports provided by a mentor predicted higher GPAs and fewer school absences among the students (Sánchez et al., 2008). These educational supports included emotional support by listening to and encouraging students, cognitive support by tutoring and giving advice, and informational support by providing specific information and sharing life experiences with students. Taken together, these findings suggest that not all mentoring relationships are equal and more research is needed to identify effective mentor relationship characteristics with Latino/a adolescents who are disproportionately exposed to risk factors for reduced academic success (Buka et al., 2001).

A primary goal of the current study is to identify specific mentoring relationship qualities that positively contribute to Latino/a youth's academic success in the context of CVE, including mentors' encouragement of positive academic and personal growth. Specifically, we examine whether academic mentor school involvement and academic mentor facilitation of positive growth are positively associated with Latino/a youth's academic engagement.

\section{Academic mentoring as a protective factor}

Not only does academic mentoring directly promote academic success among at-risk youth, but it may further benefit youth by buffering the negative effects of CVE on academic outcomes. Indeed, academic mentoring has been investigated as a protective factor for youth considered to be "at risk," including those exposed to community violence (Komosa-Hawkins, 2012). Research with at-risk racial/ethnic minority youth found that the students who participated in a school-based mentoring program showed increased competence in classroom tasks compared with their counterparts who did not participate in the mentoring program (Komosa-Hawkins, 2012). Further, researchers have tested the protective effects of specific aspects of academic mentoring, such as mentor presence, relationship quality/closeness, and relationship duration. For example, Raposa, Rhodes, \& Herrera (2016) found that mentors' confidence in their ability to mentor youth and involvement with youth in community settings buffered against environmental stressors (e.g., low socioeconomic status and parental incarceration) to predict a longer mentoring relationship, which the authors posit is key to high-quality mentoring relationships. In sum, research points to the protective benefits of academic mentoring for at-risk youth; however, it is important to 
identify which aspects of academic mentoring can be protective in the context of CVE specifically. Therefore, we examine whether academic mentor school involvement and academic mentor facilitation of positive growth moderate the relation between CVE and Latino/a youth's academic engagement.

\section{Current study}

Our study used two generative frameworks as guides: García Coll et al. (1996) integrative model of ethnic minority child development and Stanton-Salazar's (1997) social capital framework for understanding the socialization of working-class racial/ethnic minority youth. The integrative model of ethnic minority child development considers the multiple contexts in which youth of color demonstrate developmental competence and the ways that race and inequality may contribute to development. The social capital framework focuses on the ways that resources are unequally distributed, such as social networks that working-class youth of color cannot easily access. Both of these frameworks focus on the experiences of racial/ethnic minority youth and bridge multiple contexts, such as neighborhoods and schools, to offer a more complete understanding of developmental trajectories and the potential role of mentor relationships. García Coll et al. (1996) integrative model guides our hypotheses regarding the impact of neighborhood violence on youth's abilities to engage in academic contexts and acquire developmental competencies in education. Stanton-Salazar's (1997) social capital framework guides our hypotheses regarding the specific types of social capital that mentors may provide youth, including informational and institutional support captured in the constructs of mentor school involvement and mentor facilitation of growth.

The goal of the present study is to examine the protective role of academic mentoring for academic engagement of Latino/a youth exposed to community violence. Specifically, the three primary aims are to (a) examine the links between CVE and academic engagement, (b) test the associations between specific characteristics of adolescents' mentor relationships (facilitation of positive growth and school involvement) and educational outcomes (educational values, school effort, and academic efficacy); and (c) test these mentor relationship qualities as moderators of the relations between CVE and Latino/a youth's educational outcomes.

First, we hypothesize that CVE (witnessing violence and personal victimization) will be associated with lower educational values, school effort, and academic efficacy among Latino/a adolescents. Second, we expect that two specific characteristics of academic mentoring-facilitation of positive growth and school involvement-will be associated with academic engagement outcomes (higher educational values, school effort, and academic efficacy). Finally, we hypothesize that both aspects of academic mentoring will moderate the negative relations between CVE and educational outcomes. Prior research suggests that young adolescents experience closer relationships with adults (e.g., volunteering and disclosing more information) than older adolescents (DuBois et al., 2011). In addition, mentoring relationships may be particularly important for adolescents from low-income, racial/ethnic minority homes during the early high school years. Thus, our study focuses on Latino/a ninth graders attending underresourced schools.

\section{1 | METHODS}

\section{1 | Participants}

The participants for this study were drawn from a sample of 223 ninth-grade students from three high schools in two Northeastern U.S. cities. Only the students who endorsed having an academic mentor ( $n=210 ; 94 \%$ of the sample) were included in the analyses for this study. Participants' mean age was 14.5 (standard deviation $[S D]=0.69)$. The sample was $61 \%$ female $(n=137)$. All participants self-identified as Latino/a. The majority $(60 \%$; $n=135$ ) identified as having a Dominican ethnic background. Other ethnicities reported were Colombian, Mexican, and Puerto Rican. Seventy-seven percent of the sample was born in the United States, and almost half of the students were first-generation United States residents (48\%; $n=107)$. Eighty-five percent spoke both English and 
Spanish at home. Participants lived in a total of 28 different census tracts, constituting a geographically diverse sample.

The adolescent participants attended one of the three high schools (one parochial and two public schools). The second author established relationships with various urban, northeastern schools with large populations of lowincome Latino/a students and selected these schools on that basis. Two public schools and one parochial school were included in our study to capture a greater diversity of families who may enroll their children in parochial versus public schools for various reasons. None of the schools assigned specific academic mentors as part of their curriculum. One of the public schools had a unique curriculum developed around students' career interests: One division focused on math, science, and technology (MST), and the other specialized in health and human services (HHS). This public school and the parochial school were located in the same city and included the same census tracts. In comparison with the $13.5 \%$ of the entire U.S. population in $2016,31 \%$ of Latino/a residents in this district lived below the poverty line when the data were collected (U.S. Census Bureau, 2016). The violent crime rate in these census tracts was 917 per 100,000 residents as compared with the national crime rate of 373 per 100,000 residents (U.S. Department of Justice, 2016). At the parochial school, 68\% of the student population qualified for free or reduced lunch. Eighty-two percent of the total student population in the HHS track and 77 percent in the MST track qualified for free or reduced lunch. The second public school was in a different city where the violent crime rate was 573 per 100,000 residents (U.S. Department of Justice, 2006). Thirty-five percent of Latino/as in this district lived below the poverty line (U.S. Census Bureau, 2007), and $96 \%$ of the total student population qualified for free or reduced lunch.

\section{2 | Procedure}

All ninth-grade students at each school were given recruitment letters and consent forms in English and Spanish to take home to their parents. Students whose parents provided written consent completed self-report questionnaires in a quiet classroom during the school day. Students were allowed to choose whether they wanted to take the survey in Spanish or English. Seven students opted to complete the questionnaire in Spanish, and bilingual research assistants were available to assist these students. The questionnaire took approximately $2 \mathrm{hr}$ to complete, including several breaks. Each participant received a $\$ 30$ gift card to a local movie theater or shopping mall as a token of appreciation.

\section{3 | Measures}

\subsection{1 | Community violence exposure}

Students' CVE was assessed using the Survey of Exposure to Community Violence (Richters \& Martinez, 1993). Students answered 20 items that asked how often they had experienced certain violent incidents in their lifetime, using a nine-point Likert-type scale ranging from one (never) to nine (almost every day). We used subscales that distinguished between two types of violence exposure: A 10-item witnessing violence subscale ( e.g., "How many times have you seen others using or selling drugs?"), and a 10-item personal victimization subscale (e.g., "How many times have you yourself been beaten up or mugged?"). Responses on each subscale were summed to create a total witnessing violence score and a total personal victimization score, with higher scores indicating greater frequency of witnessing violence or personal victimization in the community. Participants were asked to report on experiences of violence that happened in real life and in their community, not violence is seen in the news, television, movies, video games, or within their homes between family members. The scales for witnessing violence and personal victimization reflect cumulative violence exposure and contain individual items that may or may not be related to each other. Thus, we do not assume heterogeneity of the items in these scales, and reporting internal consistency is not appropriate (Streiner, 2003). 


\subsection{2 | Academic mentor}

Students read the following definition of an academic mentor (Steinberg, Lamborn, Dornbusch, \& Darling, 1992): "Now we would like you to think about an adult in your life who you consider to be an academic mentor. That is, someone you can go to for support and guidance about school matters, someone who inspires and encourages you to do your best at school, and someone who helps you with school-related decisions. This can be a family or nonfamily member." A single item asked students: "Do you have a person like this, an academic mentor, in your life?" Students answered "yes" or "no." Students were then asked to name a person who supports and guides them the most with school. If students indicated having an academic mentor, then they answered questions about how that mentor or person was involved with school-related matters. Most of the sample-210 students (94\%)reported having an academic mentor and/or named a person who guides and helps them most with school.

\subsubsection{Academic mentor's school involvement}

Thirteen items asked how often their mentor was involved in school-related matters. Example items included, "Mentor helps with homework" and "Mentor knows how you are doing in school." All 13 items were used in this study and coded on a four-point Likert-type scale, ranging from one (never) to four (a lot). These items were based on Steinberg et al. (1992) parental school involvement scale. Scores were averaged, and higher scores indicated more mentor involvement in school matters. Cronbach's alpha was 0.89 for this scale.

\subsection{4 | Mentor's facilitation of positive growth}

If students indicated they had an academic mentor or a person who supports and guides them the most with school, they were asked questions about the extent to which their mentor facilitates positive personal and academic growth for them (Nakkula \& Harris, 2013). Participants were asked how true each of the eight items were of their relationships with their mentors. All items were coded on a four-point Likert-type scale, with a range of one (not at all true) to four (very true). Some sample items included, "Learned a lot from my mentor" and "Do better at school because of mentor's help." Scores were averaged, and higher scores reflect greater facilitation of positive personal and academic growth. Cronbach's alpha for this scale was 0.92 .

\subsection{5 | Educational values}

Students' educational values were measured using six items that assessed the perceived importance of certain educational goals (Fuligni, Witkow, \& Garcia, 2005). Sample items included rating the importance, "...that you do well in school" and "...that you go to college." Responses ranged from one (not at all important) to five (extremely important), and all scores were averaged. Higher scores indicated greater value placed on education. Cronbach's alpha was 0.86 for this scale.

\subsection{6 | School effort}

Students' effort in school was measured by Steinberg et al. (1992) classroom engagement index in addition to two items designed specifically for this study. In total, five items asked students how often they engage and try to do well in school. Some sample items are "complete all reading and homework" and "hand homework in on time." Each item was coded on a five-point Likert-type scale, ranging from one (never) to five (almost always). Scores were averaged so that the higher scores indicated greater school effort and the Cronbach's alpha was 0.73 for this scale. 


\subsection{7 | Academic efficacy}

Students' academic efficacy was measured using the Moos and Trickett's (1987) Classroom Environment Scale. This scale consisted of seven items that ask students how much they agree with statements reflecting confidence in their ability to master academic skills. Sample items included, "I'm certain I can master the skills taught in school this year" and "I can do almost all the work in school if I don't give up." Each item was coded on a five-point Likerttype scale, ranging from one (strongly disagree) to five (strongly agree). Higher average scores indicated greater academic efficacy and the scale had a Cronbach's alpha of 0.80 .

\section{2 | RESULTS}

\section{1 | Preliminary analyses}

Students in our sample reported high levels of CVE. Over $92 \%$ of students reported witnessing violence, and $87 \%$ reported being a victim of a violent event at some point during their lifetime. The most commonly reported incident of witnessing violence was seeing someone carrying a weapon $(71 \% ; n=159)$, and the most common type of personal victimization included being hit, slapped, or punched by someone $(71 \% ; n=160)$. Overall, there was a higher prevalence of witnessing violence than personal victimization in our sample.

Of the 210 students who reported having an academic mentor, 165 (79\%) noted that these people were family members. Over half of the 210 students indicated that their mentors were their parents $(52 \% ; n=108)$. Almost a quarter indicated that their mentor was nonfamilial $(22 \% ; n=45)$, and about half of these nonfamilial mentors were school employees (e.g., teacher or guidance counselor). Most students reported that their academic mentor was female $(71 \% ; n=150)$ and Latina/o $(88 \% ; n=185)$. In addition, participants reported that the mentors had a range of educational levels, $20 \%(n=41)$ with a high school diploma or general education diploma (GED) and $24 \%(n=50)$ with a college degree. Finally, most students reported that they had a relationship with their mentor for 5 years or longer $(63 \% ; n=132)$.

Table 1 shows the bivariate correlations among the independent and dependent variables examined in this study. Witnessing violence was negatively associated with school effort, educational values, and academic efficacy, ranging from -0.23 to $-0.30 ; p<0.01$. Personal victimization was also negatively correlated with all three educational outcomes, ranging from -0.22 to $-0.36 ; p<0.01$. There was a strong, significant correlation between witnessing violence and personal victimization, $r=0.77 ; p<0.01$, indicating that adolescents who reported having witnessed a high level of violence also tended to experience a high level of personal victimization. Mentor school involvement and mentor's facilitation of positive growth were moderately correlated, $r=0.49 ; p<0.01$. Finally, educational values, school effort, and academic efficacy were moderately correlated, ranging from 0.41 to $0.52 ; p<0.01$.

\section{2 | Primary analyses}

Six hierarchical linear regression analyses were conducted to separately examine the contributions of witnessing violence (Table 2) and personal victimization (Table 3) to educational values, school effort, and academic efficacy. Academic mentor school involvement and facilitation of positive growth were included in each regression to test their main effects on each of the educational outcomes, as well as their interaction with both witnessing violence and personal victimization in predicting each educational outcome. Witnessing violence, personal victimization, academic mentor school involvement, and facilitation of positive growth variables was mean-centered (Aiken \& West, 1991). Demographic control variables (age, sex, and school) were entered in the first step, and CVE (either witnessing violence or personal victimization) was entered along with mentor characteristics in the second step. Finally, in the third step, two interaction terms were entered to investigate whether academic mentor school 

กั้

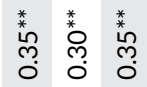

$a$

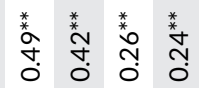

$\infty$

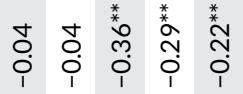

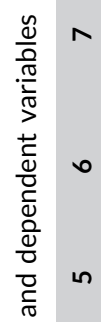

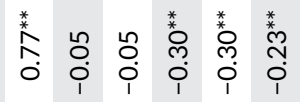

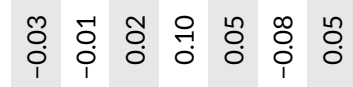
茂 $\begin{array}{llllllll}1 & 1 & 1 & 1 & 1 & 0 & 1 & 0 \\ & 0 & 0 & 0 & 0 & 0 & 0 & 0\end{array}$

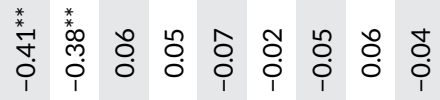
陉 


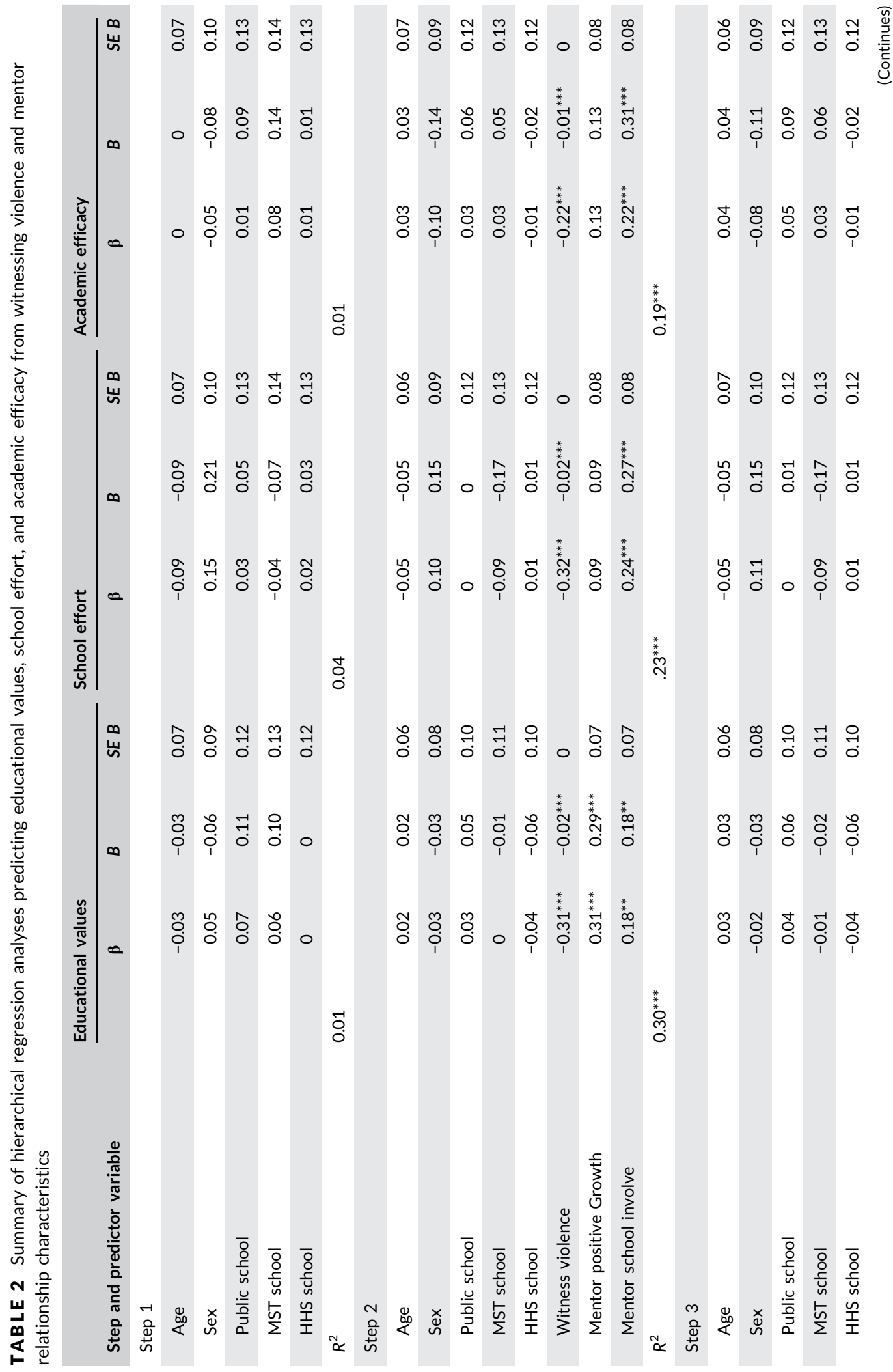




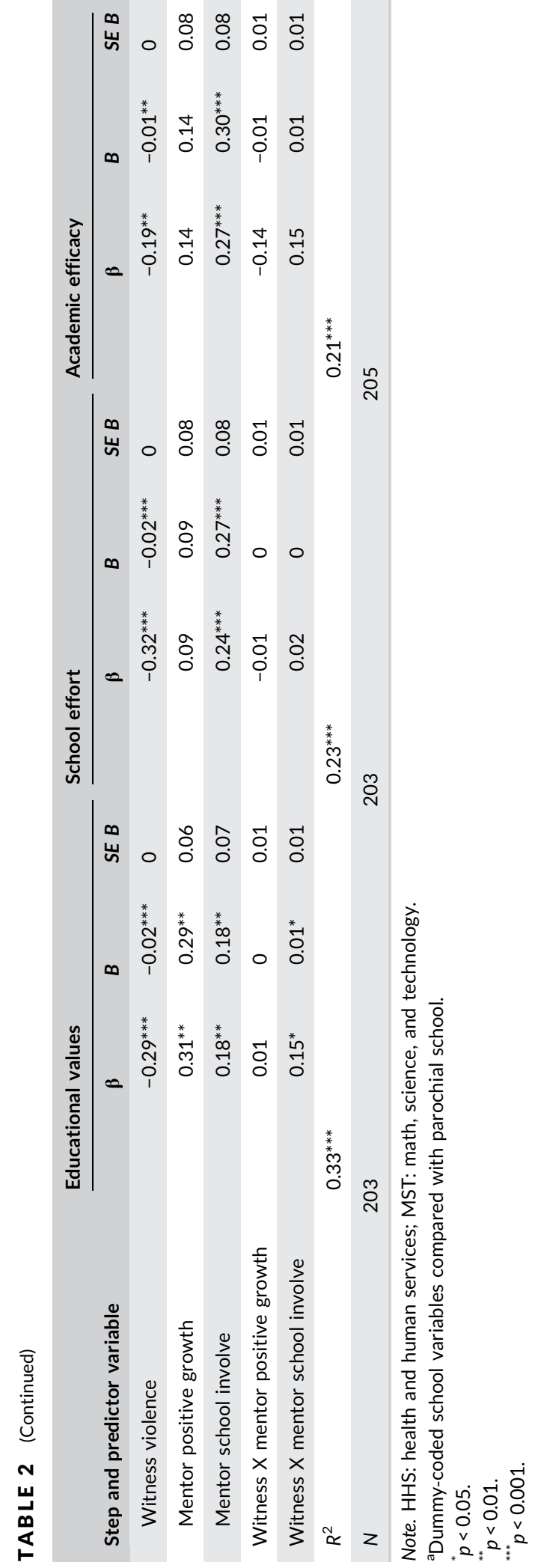




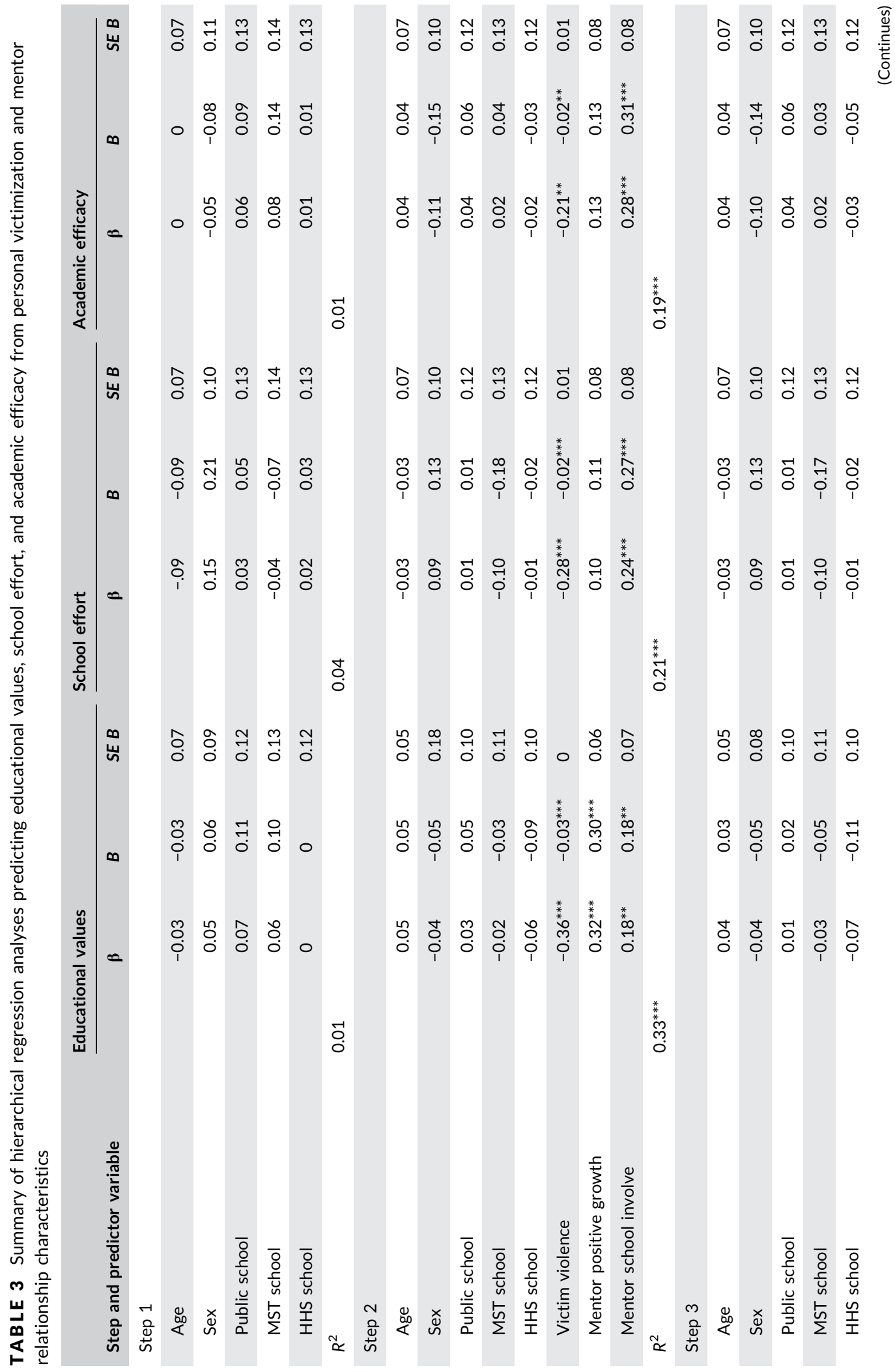




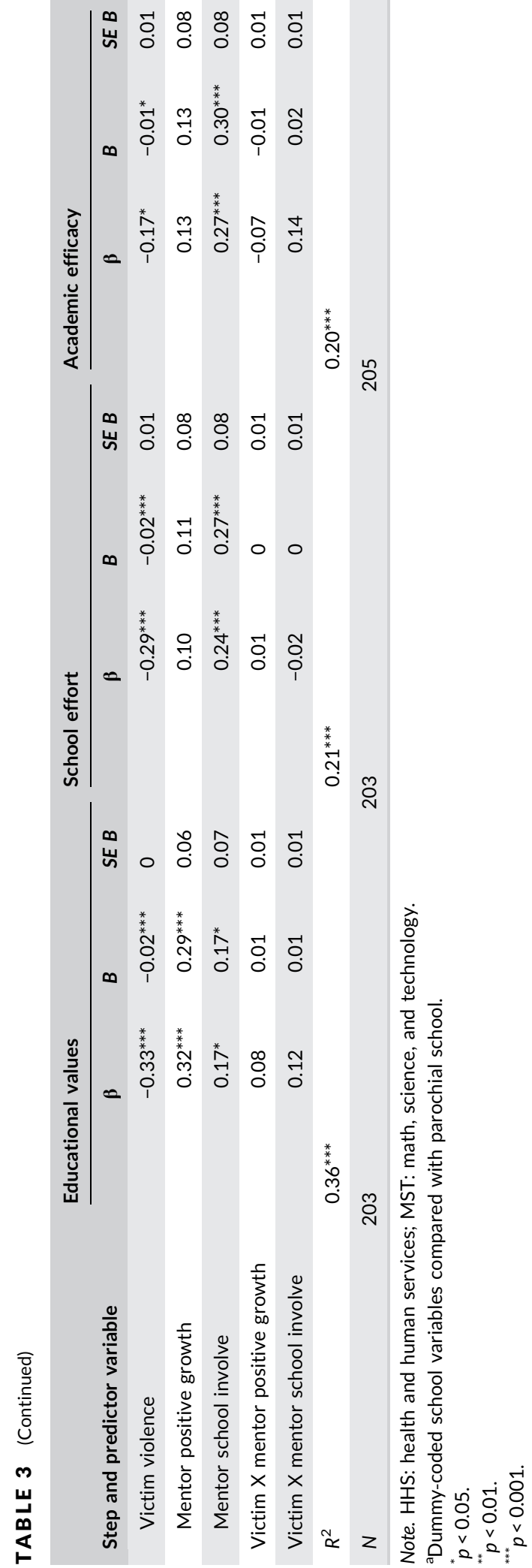


involvement and facilitation of positive growth moderated the effect of CVE on educational values, school effort, and academic efficacy. We used model 1 (simple moderation model) of an SPSS PROCESS macro (Hayes, 2013) to probe conditional effects at low (1SD below the mean), mean, and high (1SD above the mean) levels of the moderator variable for significant interactions.

\subsection{1 | Witnessing violence}

Table 2 shows the results of the regression analyses for demographic covariates, witnessing violence, and academic mentor relationship characteristics predicting educational values, school effort, and academic efficacy. The results of the model predicting educational values yielded significant main effects and one significant interaction effect. In Step 1, none of the covariates were significantly associated with educational values. As hypothesized, in Step 2, witnessing violence was negatively related to educational values. Specifically, a unit increase in witnessing violence was associated with a 0.31-unit decrease in educational values. In addition, mentor facilitation of growth and mentor school involvement were each significantly associated with greater educational values, but larger unstandardized coefficients were observed for mentor facilitation of growth than mentor school involvement. Specifically, a unit increase in mentor facilitation of growth was associated with a 0.31-unit increase in educational values, compared with a 0.18-unit increase in educational values associated with mentor school involvement. Together, these predictors accounted for significantly more variance in educational values compared with the demographic covariates alone $\left(\Delta R^{2}=0.30 ; p<0.001\right)$. In Step 3, the interaction between witnessing violence and academic mentor's school involvement was significantly related to educational values, suggesting that the mentor's school involvement moderated the negative relation between witnessing violence and educational values. Witnessing violence was significantly and negatively related to educational values at low, mean, and high levels of mentor school involvement, but the association grew weaker as mentor school involvement increased. Specifically, a unit increase in mentor school involvement was associated with a 0.15-unit increase in the relation between witnessing violence and educational values. The interaction between witnessing violence and academic mentor's facilitation of positive growth was not significantly related to educational values. Together, the interaction terms in Step 3 explained a significantly greater portion of the variance in educational values compared with Step 2 $\left(\Delta R^{2}=0.02 ; p<0.05\right)$.

The results of the models predicting school effort and academic efficacy were highly similar and supported several main effects hypotheses. None of the covariates in Step 1 were significantly related to either outcome. In Step 2, witnessing violence and the mentor relationship characteristics together explained significantly more variance in school effort $\left(\Delta R^{2}=0.20, p<0.001\right)$ and academic efficacy $\left(\Delta R^{2}=0.18 ; p<0.001\right)$ than the demographic covariates alone. As hypothesized, witnessing violence was negatively associated with school effort and academic efficacy. Specifically, a unit increase in witnessing violence was associated with a 0.32-unit decrease in school effort and a 0.22-unit decrease in academic efficacy. In addition, mentor school involvement was positively related to both outcomes, but academic mentor's facilitation of positive growth was not related to either outcome. Specifically, a unit increase in mentor school involvement was associated with a 0.24-unit increase in school effort and a 0.22-unit increase in academic efficacy. In Step 3, neither of the interaction terms were significantly related to school effort or academic efficacy.

\subsection{2 | Personal victimization}

Table 3 shows the results of the regression analyses for demographic covariates, personal victimization, and academic mentor relationship factors predicting educational values, school effort, and academic efficacy. The model predicting educational values yielded significant main effects but nonsignificant interaction effects. Specifically, none of the covariates were significantly associated with educational values in Step 1. In Step 2, as hypothesized, personal victimization was negatively associated with educational values. We observed a large unstandardized regression coefficient, such that a unit increase in personal victimization was associated with a 0.36 -unit decrease 
in educational values. In addition, both mentor facilitation of growth and mentor school involvement were positively associated with educational values. We observed larger unstandardized coefficients for mentor facilitation of positive growth than mentor school involvement, which were associated with 0.32-unit and a 0.18unit increase in educational values, respectively. Together, personal victimization and mentor characteristics explained significantly more variance in educational values compared with the demographic $\operatorname{covariates}\left(\Delta R^{2}=0.33\right.$; $p<0.001$ ). In Step 3, neither of the interaction terms were significantly related to educational values.

Results of the models predicting school effort and academic efficacy were highly similar: Main effects were significant, but interaction effects were nonsignificant. None of the covariates were significantly associated with school effort or academic efficacy. In Step 2, personal victimization and the two mentor relationship characteristics explained significantly more variance than the demographic variables alone. As hypothesized, personal victimization was significantly and negatively associated with both school effort and academic efficacy. Personal victimization was associated with a larger decrease in school effort than academic efficacy according to the unstandardized regression coefficients. Specifically, personal victimization was associated with a 0.29-unit decrease in school effort and a 0.21-unit decrease in academic efficacy. In addition, like the results for witnessing violence, academic mentor's school involvement was significantly and positively related to both outcomes. Specifically, mentor school involvement was associated with a 0.24-unit increase in school effort and a 0.28-unit increase in academic efficacy. However, the academic mentor's facilitation of positive growth was not related to either outcome. Neither of the interaction terms in Step 3 was significantly associated with either school effort or academic efficacy.

\section{3 | DISCUSSION}

The current study tested (a) whether CVE negatively influenced academic engagement, (b) whether two academic mentoring characteristics-mentor school involvement and mentor facilitation of growth-were associated with academic engagement, and (c) whether the mentoring characteristics moderated the relations between CVE and Latino/a adolescents' academic engagement. First, as expected, we found that both witnessing violence and victimization were negatively associated with all three academic outcomes-educational values, school effort, and academic efficacy. These findings are in line with prior research demonstrating negative associations between CVE and academic outcomes (Borofsky et al., 2013; Henrich et al., 2004). These findings also support the integrative model of ethnic minority child development (1996) in that neighborhoods affected by violence are likely to impact Latino/a youth's developmental competencies. In addition, recent research found that youth with low socioeconomic status report lower academic achievement, and this relation was mediated by CVE (Ruiz, McMahon, \& Jason, 2018). It may be the case that CVE interrupts low-income racial/ethnic minority youth's ability to focus or engage in school both directly (Borofsky et al., 2013) and indirectly by fostering negative psychological symptoms of anxiety, depression, and PTSD (Kennedy \& Ceballo, 2013).

Second, we found that mentor school involvement was positively related to all the three academic outcomes as we hypothesized, but mentor facilitation of growth was positively related to educational values only. These findings contribute to a growing body of literature that focuses on specific qualities of academic mentoring relationships (Raposa et al., 2016; Sánchez et al., 2008), suggesting that mentor school involvement is implicated in a broader range of educational outcomes than mentor facilitation of growth. It is likely that mentors' involvement in students' school matters communicates the importance of valuing and investing in education. This investment on the part of mentors may, in turn, encourage students to recognize the importance of education and achievement in school. In addition, more tangible forms of support tapped by mentor school involvement (e.g., being present in the school and speaking with teachers on behalf of the mentee) may be more of a contribution to students' academic engagement than intangible forms of support, which may be harder to translate to concrete outcomes for students. Similarly, Sánchez et al. (2008) found that intangible forms of educational support provided by mentors (e.g., encouragement 
and advice) were not associated with positive academic outcomes among Latino/a youth. However, a combination of tangible and intangible forms of educational support was associated with positive academic outcomes. Thus, interventions aimed at increasing Latino/a students' academic success might benefit from including tangible forms of mentor support (e.g., strong mentor school involvement) rather than solely intangible forms of support (e.g., mentor facilitation of positive growth). These forms of concrete mentor support may be most effective by targeting malleable attitudes about the value of education, bolstering students' academic confidence, and encouraging behaviors that promote positive academic outcomes for students.

Third, not only was mentor school involvement associated with more positive academic outcomes than mentor facilitation of positive growth, but we also found that mentor school involvement buffered the negative relation between witnessing violence and Latino/a youth's educational values. Specifically, witnessing violence had a significant negative relation with educational values at low, mean, and high levels of mentor school involvement, but the relation grew weaker as students reported more mentor school involvement. Thus, mentor school involvement appears to be protective for Latino/a adolescents in the context of CVE. Academic mentoring is protective against the effects of other risk factors for racial/ethnic minority youth (Komosa-Hawkins, 2012; Raposa et al., 2016), but this is the first study to our knowledge to investigate the role of mentor school involvement in buffering the effects of CVE on academic engagement. Given the findings that mentors were overwhelmingly Latino/a and related to students, it may be that mentors also have experience with community violence and can, therefore, serve as role models to youth coping with CVE. Thus, mentors' investment in their mentees' education, given mentors' own possible experiences with community violence, may be communicating the importance of education in the face of community violence. Future research would benefit from investigating the ways that important adults discuss exposure to community violence and education with youth, which might further elucidate the connection between mentors' presence in the school and participation in educational activities and the values these behaviors communicate about education to Latino/a youth.

The attenuating impact of mentor school involvement supports Stanton-Salazar's (1997) social capital framework, which posits that mentors providing academic task-specific knowledge (e.g., helping with homework and selecting challenging courses) and organizational knowledge (e.g., discussing college funding) are types of social capital that promote positive academic outcomes for youth in high-risk contexts. This finding also underscores the importance of facilitating important adults' participation in Latino/a youth's educational settings. A plethora of research investigates ways to involve important adults in students' educational activities, but this study emphasizes the importance of tangible mentor school involvement for violence-exposed Latino/a youth in particular. Thus, special attention to cultural barriers that may exclude adults that are important to low-income Latino/a youth, such as language barriers and school activities during work hours, are especially important to consider. For example, Hornby and Lafaele (2011) theorized that parental involvement in schools is hampered by the lack of attention paid to ethnicity and culture discrepancies between schools and student families' values. They argue that efforts to involve parents continue to be marginally successful because they do not respect the cultural values of families of working-class youth of color, including cultivating trust and translating school communication in languages besides English. These barriers likely apply to academic mentors in Latino/a students' lives.

\section{1 | Limitations}

As with all research, it is important to note the limitations of the current study. First, our study did not include a random sampling of schools or participants. Second, with a sample of mostly low-income, Dominican American, ninth-grade students living in northeastern cities, our findings are not generalizable to all Latino/a youth's experiences. It is important to emphasize the immense heterogeneity among Latino/a families, including diverse immigration histories, socioeconomic statuses, and educational backgrounds. Some research suggests that language barriers and school hours that conflict with work schedules interfere with immigrant Dominican families' ability to engage with their children's schools (García Coll et al., 2002). Given these barriers, our findings highlight the 
important role of academic mentoring for this sample of mostly Dominican students and familial mentors. Future studies would benefit from including Latino/a youth of other nationalities and from other neighborhood settings to understand how academic mentoring may serve a protective function for Latino/a youth exposed to community violence.

Third, the method of identifying academic mentors in this study allowed students to report that they did not have a mentor. Although the majority of the sample reported having an academic mentor, this study includes only those students who named an academic mentor. Thus, while our method allowed us to parse out the unique contributions of specific mentoring characteristics among mentored students, the findings may not generalize to students who have no mentor at all. Future research should investigate the conditions under which new mentoring relationships flourish and how best to connect students with mentors who will be highly involved in their education. An interesting tension exists between researchers' and youth's definitions of academic mentoring, and the potential implications of researchers who limit the people who can "count" as an academic mentor. Our definition of academic mentorship (i.e., someone who guides you and helps the most with school matters) may not match Latino/ a youth's definitions of academic mentorship. Future research should explore how youth define academic mentoring and effective mentoring relationships with the use of qualitative methods that allow for more participant-informed analyses. Fourth, this study used cross-sectional data to test the relations among CVE, academic mentoring characteristics, and academic engagement. As such, we are limited in the conclusions we can draw about the direction of the associations. Research on CVE and academic outcomes would benefit from longitudinal studies that assess how academic mentoring bolsters or protects academic engagement in the context of chronic CVE over time.

\section{CONCLUSIONS AND IMPLICATIONS}

The current study found that CVE is negatively related to academic engagement, namely educational values, school effort, and academic efficacy. One specific characteristic of academic mentoring-mentor school involvement-was most robustly linked to all the three academic engagement outcomes, and further buffered the negative relation between witnessing community violence and educational values. Our findings highlight the importance of culturally appropriate models of mentoring for racial/ethnic minority youth. In theory and in research, mapping and studying culturally relevant aspects of academic mentoring relationships can provide policymakers and practitioners with evidence that encourages mentoring programs to attend to relations of privilege and power. In doing so, these programs might be able to cultivate more effective and trusting relationships between mentors and mentees that facilitate mentor school involvement. Given that the majority of mentors identified by youth in our study were familial, school administrators and teachers should work closely with families of Latino/a youth to encourage involvement in school matters and extracurricular activities. This could include increasing mentors' access to teachers, school curriculum, homework material, and other school-related resources, such as course schedules. Moreover, mentor school involvement could be further facilitated by ensuring that there are translation and literacy services available for families of Latino/a youth. Our study suggests that mentor school involvement would be especially important for urban-residing, low-income Latino/a youth who are exposed to community violence. In addition, clinical interventions with Latino/a youth exposed to community violence might benefit from incorporating and maintaining a focus on education. Given the negative relation between CVE and academic engagement in our sample, Latino/a youth may benefit from discussions that affirm their potential for academic success in the context of CVE.

\section{ORCID}




\section{REFERENCES}

Aiken, L. S., \& West, S. G. (1991). Multiple regression: Testing and interpreting interactions. Newbury Park, CA: Sage Publications.

Arellano, A. R., \& Padilla, A. M. (1996). Academic invulnerability among a select group of Latino university students. Hispanic Journal of Behavioral Sciences, 18(4), 485-507.

Borofsky, L. A., Kellerman, I., Baucom, B., Oliver, P. H., \& Margolin, G. (2013). Community violence exposure and adolescents' school engagement and academic achievement over time. Psychology of Violence, 3(4), 381-395. https:// doi.org/10.1037/a0034121

Buka, S. L., Stichick, T. L., Birdthistle, I., \& Earls, F. J. (2001). Youth exposure to violence: Prevalence, risks, and consequences. American Journal of Orthopsychiatry, 71(3), 298-310.

Ceballo, R. (2004). From barrios to Yale: The role of parenting strategies in Latino families. Hispanic Journal of Behavioral Sciences, 26(2), 171-186.

Ceballo, R., Huerta, M., \& Epstein-Ngo, Q. (2010). Parental and school influences promoting academic success among Latino students. In J. L. Meece, \& J. S. Eccles (Eds.), Handbook of research on schools, schooling, and human development (pp. 293307). New York, NY: Routledge.

Crouch, J. L., Hanson, R. F., Saunders, B. E., Kilpatrick, D. G., \& Resnick, H. S. (2000). Income, race/ethnicity, and exposure to violence in youth: Results from the national survey of adolescents. Journal of Community Psychology, 28(6), 625-641.

DuBois, D. L., \& Silverthorn, N. (2005). Natural mentoring relationships and adolescent health: Evidence from a national study. American Journal of Public Health, 95, 518-524.

DuBois, D. L., Portillo, N., Rhodes, J. E., Silverthorn, N., \& Valentine, J. C. (2011). How effective are mentoring programs for youth? A systematic assessment of the evidence. Psychological Science in the Public Interest, 12(2), 57-91.

Fowler, P. J., Tompsett, C. J., Braciszewski, J. M., Jacques-Tiura, A. J., \& Baltes, B. B. (2009). Community violence: A metaanalysis on the effect of exposure and mental health outcomes of children and adolescents. Development and Psychopathology, 21(1), 227-259.

Fuligni, A. J., Witkow, M., \& Garcia, C. (2005). Ethnic identity and the academic adjustment of adolescents from Mexican, Chinese, and European backgrounds. Developmental Psychology, 41(5), 799-811.

García Coll, C., Akiba, D., Palacios, N., Bailey, B., Silver, R., DiMartino, L., \& Chin, C. (2002). Parental involvement in children's education: Lessons from three immigrant groups. Parenting: Science and Practice, 2(3), 303-324.

García Coll, C., Crnic, K., Lamberty, G., Wasik, B. H., Jenkins, R., Vázquez García, H., \& McAdoo, H. P. (1996). An integrative model for the study of developmental competencies in minority children. Child Development, 67, 1891-1941.

Henrich, C. C., Schwab-Stone, M., Fanti, K., Jones, S. M., \& Ruchkin, V. (2004). The association of community violence exposure with middle-school achievement: A prospective study. Journal of Applied Developmental Psychology, 25(3), 327-348.

Hayes, A. F. (2013). Introduction to mediation, moderation, and conditional process analysis: A regression-based approach, New York: Guilford Press.

Herrera, C., DuBois, D. L., \& Grossman, J. B. (2013). The Role of Risk: Mentoring Experiences and Outcomes for Youth with Varying Risk Profiles. New York, NY: A public/private ventures project distributed by MDRC.

Hornby, G., \& Lafaele, R. (2011). Barriers to parental involvement in education: An explanatory model. Educational Review, 63(1), 37-52. https://doi.org/10.1080/00131911.2010.488049

Hurd, N. M., Sánchez, B., Zimmerman, M. A., \& Caldwell, C. H. (2012). Natural mentors, racial identity, and educational attainment among African American adolescents: Exploring pathways to success. Child Development, 83(4), $1196-1212$.

Jocson, R. M., Alers-Rojas, F., Ceballo, R., \& Arkin, M. (2018). Religion and spirituality: Benefits for Latino adolescents exposed to community violence. Youth \& Society, (advance online publication), https://doi.org/0044118X18772714

Kennedy, T. M., \& Ceballo, R. (2013). Latino adolescents' community violence exposure: After-school activities and familismo as risk and protective factors. Social Development, 22, 663-682. https://doi.org/10.1111/sode.12030

Kennedy, T. M., \& Ceballo, R. (2014). Who, what, when, and where? Toward a dimensional conceptualization of community violence exposure. Review of General Psychology, 18, 69-81. https://doi.org/10.1037/gpr0000005

Komosa-Hawkins, K. (2012). The impact of school-based mentoring on adolescents' social-emotional health. Mentoring \& Tutoring: Partnership in Learning, 20(3), 393-408.

Lyons, M. D., \& McQuillin, S. D. (2018). Risks and rewards of school-based mentoring relationships: A reanalysis of the student mentoring program evaluation. School Psychology Quarterly, 34, 76-85. https://doi.org/10.1037/spq0000265

Moos, R. H., \& Trickett, E. (1987). Classroom Environment Scale Manual: CES. Palo Alto, CA: Consulting Psychologists Press.

Morales, E. E. (2010). Linking strengths: Identifying and exploring protective factor clusters in academically resilient lowsocioeconomic urban students of color. Roeper Review, 32(3), 164-175.

Nakkula, M. J., \& Harris, J. T. (2013). Assessing mentoring relationships. Handbook of youth mentoring, 45-62.

Poquiz, J. L., \& Fite, P. J. (2018). Community violence exposure, conduct problems, and oppositional behaviors among Latino adolescents: The moderating role of academic performance. Child \& Youth Care Forum, 47(3), 377-389. 
Raposa, E. B., Rhodes, J. E., \& Herrera, C. (2016). The impact of youth risk on mentoring relationship quality: Do mentor characteristics matter? American Journal of Community Psychology, 57(3-4), 320-329.

Richters, J. E., \& Martinez, P. (1993). The NIMH community violence project: Children as victims of and witnesses to violence. Psychiatry, 56, 7-21.

Ruiz, L. D., McMahon, S. D., \& Jason, L. A. (2018). The role of neighborhood context and school climate in school-level academic achievement. American Journal of Community Psychology, 61(3-4), 296-309. https://doi.org/10.1002/ajcp. 12234

Sánchez, B., Esparza, P., \& Colón, Y. (2008). Natural mentoring under the microscope: An investigation of mentoring relationships and Latino adolescents' academic performance. Journal of Community Psychology, 36(4), 468-482.

Schwartz, D., \& Gorman, A. H. (2003). Community violence exposure and children's academic functioning. Journal of Educational Psychology, 95(1), 163-173. https://doi.org/10.1037/0022-0663.95.1.163

Secada, W. G., Chavez-Chavez, R., Garcia, E., Muñoz, C., Oakes, J., Santiago-Santiago, I., \& Slavin, R. (1998). No more excuses: The final report of the Hispanic dropout project. MDRC

Spencer, R., \& Rhodes, J. E. (2014). Growth promoting relationships with children and adolescents. New Directions for Youth Development, 2014(144), 59-72. https://doi.org/10.1002/yd.20113

Stanton-Salazar, R. (1997). A social capital framework for understanding the socialization of racial minority children and youths. Harvard Educational Review, 67(1), 1-41.

Stanton-Salazar, R. D., \& Spina, S. U. (2003). Informal mentors and role models in the lives of urban Mexican-origin adolescents. Anthropology \& Education Quarterly, 34(3), 231-254.

Steinberg, L., Lamborn, S. D., Dornbusch, S. M., \& Darling, N. (1992). Impact of parenting practices on adolescent achievement: Authoritative parenting, school involvement, and encouragement to succeed. Child Development, 63(5), 1266-1281.

Streiner, D. L. (2003). Being inconsistent about consistency: When coefficient alpha does and doesn't matter. Journal of Personality Assessment, 80, 217-222.

U.S. Census Bureau. (2007). The American community-Hispanics: 2004. American Community Survey Reports (ACS-03). Washington DC: Government Printing Office.

U.S. Census Bureau. (2016). Income and Poverty in the U.S.: 2015 (Report No. P60-256). Washington, DC Government Printing Office.

U.S. Department of Justice (2006). Uniform Crime Report: Crime in the United States, 2006. Retrieved from Federal Bureau of Investigation Web Site: http://www.fbi.gov/ucr/cius2006/offenses/violent_crime/index.html. (Accessed May 20, 2008).

U.S. Department of Justice (2016). Uniform crime report: Crime in the United States, 2015. Retrieved from https://ucr.fbi.gov/crimein-the-u.s/2015/crime-in-the-u.s.-2015/offenses-known-to-law-enforcement/violent-crime. (Accessed June 21, 2017).

York, T. T., Gibson, C., \& Rankin, S. (2015). Defining and measuring academic success. Practical Assessment, Research \& Evaluation, 20, 5.

Zimmerman, M. A., Bingenheimer, J. B., \& Notaro, P. C. (2002). Natural mentors and adolescent resiliency: A study with urban youth. American Journal of Community Psychology, 30(2), 221-243.

How to cite this article: Fike KJ, Ceballo R, Kennedy TM. The role of academic mentors for Latino/a adolescents exposed to community violence. J Community Psychol. 2019;47:1329-1346.

https://doi.org/10.1002/jcop.22189 